\title{
Interactions between uncoupling protein 2 gene polymorphisms, obesity and alcohol intake on liver function: a large meta-analysed population-based study
}

\author{
Karani S Vimaleswaran ${ }^{1,2}$, Alana Cavadino ${ }^{2,3}$, Niek Verweij ${ }^{4}$, Ija M Nolte ${ }^{5}$, \\ Irene Mateo Leach4, LifeLines Cohort Study ${ }^{\ddagger}$ Juha Auvinen ${ }^{6,7}$, Juha Veijola ${ }^{8,9}$, \\ Paul Elliott ${ }^{10}$, Brenda W Penninx ${ }^{11,12}$, Harold Snieder ${ }^{5}$, Marjo-Riitta Järvelin 6,7,10,13, \\ Pim van der Harst ${ }^{4,14,15}$, Robert D Cohen ${ }^{16,+}$, Barbara J Boucher ${ }^{16}$ and \\ Elina Hyppönen $2,17,18$
}

\footnotetext{
${ }^{1}$ Hugh Sinclair Unit of Human Nutrition, Department of Food and Nutritional Sciences, School of Chemistry, Food and Pharmacy, University of Reading, Whiteknights, PO Box 226, Reading RG6 6AP, UK, 'Population, Policy and Practice, UCL Institute of Child Health, London, UK, ${ }^{3}$ Wolfson Institute of Preventive Medicine, Centre for Environmental and Preventive Medicine, Queen Mary University of London, London, UK, Departments of ${ }^{4}$ Cardiology and ${ }^{5}$ Epidemiology, University Medical Center Groningen, University of Groningen, Groningen, The Netherlands, ${ }^{6}$ Unit of Primary Care, Oulu University Hospital, Oulu, Finland, ${ }^{7}$ Faculty of Medicine, Center for Life Course Epidemiology and ${ }^{8}$ Department of Psychiatry, Center for Clinical Neuroscience, University of Oulu, Oulu, Finland, ${ }^{9}$ Department of Psychiatry, Medical Research Center, University Hospital of Oulu, Oulu, Finland, ${ }^{10}$ Department of Epidemiology and Biostatistics, Imperial College London, MRC-PHE Centre for Environment and Health, London, UK, ${ }^{11}$ Department of Psychiatry, Leiden University Medical Center, Leiden, The Netherlands, ${ }^{12}$ Department of Psychiatry, EMGO Institute of Health and Care Research, Neuroscience Campus Amsterdam, VU University Medical Center, Amsterdam, The Netherlands,

${ }^{13}$ Biocenter Oulu, University of Oulu, Oulu, Finland, ${ }^{14}$ Department of Genetics, University Medical Center Groningen, University of Groningen, Groningen, The Netherlands, ${ }^{15} \mathrm{ICIN}$ - Netherlands Heart Institute, Durrer Center for Cardiogenetic Research, Utrecht, The Netherlands, ${ }^{16}$ Barts and The London School of Medicine and Dentistry, Queen Mary University of London, Blizard Institute, Newark Street, London, UK, ${ }^{17}$ Centre for Population Health Research, School of Health Science and Sansom Institute of Health Research, University of South Australia, Adelaide, South Australia, Australia and ${ }^{18}$ South Australian Health and Medical Research Institute, Adelaide, South Australia, Australia

${ }^{\dagger}(\mathrm{R} D$ Cohen deceased October 2014)

${ }^{\ddagger}$ (The details of the LifeLines Cohort Study is presented in the Acknowledgements section)
}

Correspondence should be addressed to K S Vimaleswaran Email

v.karani@reading.ac.uk

\begin{abstract}
Background and objective: Given the role of uncoupling protein 2 (UCP2) in the accumulation of fat in the hepatocytes and in the enhancement of protective mechanisms in acute ethanol intake, we hypothesised that UCP2 polymorphisms are likely to cause liver disease through their interactions with obesity and alcohol intake. To test this hypothesis, we investigated the interaction between tagging polymorphisms in the UCP2 gene (rs2306819, rs599277 and rs659366), alcohol intake and obesity traits such as BMI and waist circumference (WC) on alanine aminotransferase (ALT) and gamma glutamyl transferase (GGT) in a large meta-analysis of data sets from three populations ( $n=20242)$.

Design and methods: The study populations included the Northern Finland Birth Cohort $1966(n=4996)$, Netherlands Study of Depression and Anxiety $(n=1883)$ and LifeLines Cohort Study $(n=13363)$. Interactions between the polymorphisms and obesity and alcohol intake on dichotomised ALT and GGT levels were assessed using logistic regression and the likelihood ratio test.

Results: In the meta-analysis of the three cohorts, none of the three UCP2 polymorphisms were associated with GGT or ALT levels. There was no evidence for interaction between the polymorphisms and alcohol intake on GGT and ALT levels. In contrast, the association of WC and BMI with GGT levels varied by rs659366 genotype ( $P_{\text {interaction }}=0.03$ and 0.007 , respectively; adjusted for age, gender, high alcohol intake, diabetes, hypertension and serum lipid concentrations).
\end{abstract}

C) 2015 The authors Published by Bioscientifica Ltd

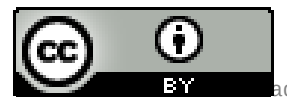

This work is licensed under a Creative Commons Attribution 3.0 Unported License. 
Conclusion: In conclusion, our findings in 20242 individuals suggest that UCP2 gene polymorphisms may cause liver dysfunction through the interaction with body fat rather than alcohol intake.

\section{Introduction}

Uncoupling protein 2 (UCP2) is a heat-generating mitochondrial inner-membrane carrier protein that is widely expressed in tissues including adipocytes (1) and liver micro-lobules (2). Although liver is the major site of UCP2 expression in the rodent foetus, the levels decline soon after birth (3). However, under pathologic conditions such as during inflammation (4) or steatosis, it increases (5); UCP2 gene expression has also been shown to occur in the hepatocytes of both normal adult rodents and healthy human adults, in the central area of the lobules (2). The role of UCP2 in obesity and liver disease is substantiated by the evidence that UCP2 enhanced fat accumulation in the liver, increased insulin resistance (6) and stimulated protective peripheral and central neural mechanisms in acute ethanol intake (7)

Polymorphisms within the UCP2 gene have been shown to be associated with various metabolic traits such as obesity $(8,9)$ and type 2 diabetes $(10,11)$. Although the effects of these polymorphisms on UCP2 function are still unclear, it could be hypothesised that the loss-of-function polymorphisms are likely to contribute to type 2 diabetes as a result of lower hepatic glucose uptake (12). This is due to reduced glucose reabsorption in the central areas of liver lobules, where this normally occurs (13) - a suggestion supported by the report of reduced type 2 diabetes risk with one UCP2 polymorphism (14). There could also be an increase in the risk of metabolic acidosis due to the switch of ammonia detoxification from glutamine synthesis to ureogenesis (15). The gainof-function polymorphisms in the UCP2 gene could cause damage of centrilobular cells due to repeated episodes of undue hyperthermia, which is likely to occur during ethanol ingestion but not in non-drinkers (16).

Based on the hypothesis that UCP2 gene polymorphisms can act as possible modulators of increases in liver enzymes through either fat accumulation or alcohol intake, we tested for the interaction effects between tagging single-nucleotide polymorphisms (tagSNPs) in the UCP2 gene and alcohol intake and obesity traits on alanine aminotransferase (ALT) and gamma glutamyl transferase (GGT), commonly used indicators of liver function, in a large meta-analysis of data sets from three populations (total $n$ up to 20242 ).

\section{Subjects and methods}

Study participants from three studies - namely, the Northern Finland Birth Cohort 1966 (NFBC 1966; $n$ up to 4996), Netherlands Study of Depression and Anxiety (NESDA; $n$ up to 1883 ) and LifeLines Cohort Study ( $n$ up to 13 363) - were included in the meta-analysis.

\section{Data collection}

NFBC 1966 was originally designed to study factors affecting pre-term birth, low birth weight and subsequent morbidity and mortality (17). Mothers living in the two Northern-most provinces of Finland were invited to participate if they had expected delivery dates during 1966. A total of 12058 live births were included in the study. At age 31, all individuals still living in the Helsinki area or Northern Finland were asked to participate in a detailed biological and medical examination $(n=6007)$ as well as a questionnaire. The sample size available for the present study was 5292 with data on genetic and phenotypic information. Written informed consent was obtained from all of the participants and the Ethics Committee of the Faculty of Medicine at the University of Oulu approved the study.

Netherlands Study of Depression and Anxiety $~$ NESDA is a multicentre study (18) designed to examine the longterm course and consequences of depressive and anxiety disorders (http://www.nesda.nl). NESDA included both individuals with depressive and/or anxiety disorders and controls without psychiatric conditions. Inclusion criteria were age 18-65 years and self-reported western European ancestry; exclusion criteria were not being fluent in Dutch and having a primary diagnosis of another psychiatric condition (psychotic disorder, obsessive compulsive 
disorder, bipolar disorder or severe substance use disorder). The sample size available for the present study was 1925 with data on genetic and phenotypic information. Written informed consent was obtained from all the participants and the study was approved centrally by the Ethical Review Board of the VU University Medical Center and subsequently by local review boards of each participating centre.

LifeLines Cohort Study - LifeLines is a multidisciplinary prospective population-based cohort study examining, in a unique three-generation design, the health and healthrelated behaviours of 167729 persons living in the northeast region of The Netherlands. It employs a broad range of investigative procedures in assessing the biomedical, socio-demographic, behavioural, physical and psychological factors that contribute to the health and disease of the general population, with a special focus on multimorbidity and complex genetics. The sample size available for the present study was 13363 with data on genetic and phenotypic information. The LifeLines study has been approved by the review board of the University Medical Center, Groningen, and adheres to the principles expressed in the Declaration of Helsinki. All study participants provided written informed consent.

\section{Measurement of clinical parameters and variables}

Northern Finland Birth Cohort 1966 Anthropometric measures, including height, weight and waist circumference (WC), were measured without shoes and in underwear by a trained nurse. BMI was calculated as weight $(\mathrm{kg}) /$ height $(\mathrm{m})^{2}$. The usage of alcohol was assessed by questionnaire (19). The alcohol variable was measured in $\mathrm{g} /$ day, calculated by the product of the frequency of how often alcoholic drinks are taken, which is converted to the proportion of days when drinking per year, the number of glasses taken when drinking and 12 (the average amount of grams of alcohol in a glass). ALT and GGT levels were measured by the Roche/Hitachi Modular Analyzer.

Netherlands Study of Depression and Anxiety $~$ Individuals who used antidepressants (not serotonin-specific reuptake inhibitors) were excluded from the analyses. Height, weight and WC were measured during a medical examination. BMI was calculated as weight $(\mathrm{kg}) /$ height $(\mathrm{m})^{2}$. Data on alcohol use were collected using the Alcohol Use Disorder Identification Test questionnaire. The alcohol variable was measured in $\mathrm{g} / \mathrm{day}$, calculated by the product of the frequency of how often alcoholic drinks are taken, which is converted to the proportion of days when drinking per year, the number of glasses taken when drinking and 12 (the average amount of grams of alcohol in a glass). Liver enzyme levels were determined with Roche Diagnostic assays.

LifeLines Cohort Study - Height, weight and WC were measured during the nurse visit without shoes and in light clothing. BMI was calculated as weight $(\mathrm{kg}) /$ height $(\mathrm{m})^{2}$. The alcohol variable was measured in number of glasses per month and subsequently converted to grams of alcohol per day using an average of $10 \mathrm{~g}$ alcohol/glass (10 $\mathrm{g}$ a day was based on the Dutch estimations of a glass per day). GGT and ALT plasma levels were determined by routine clinical chemistry at the UMCG (Groningen, The Netherlands) using the Roche/Hitachi Modular System (Roche).

\section{TagSNP selection}

TagSNPs in the UCP2 gene were selected using genotype data from the International HapMap collected in individuals of Northern and Western European ancestry (CEU; HapMap data release 24/phase II Nov 08, on NCBI B36 assembly, dbSNP b126). The Haploview Software V3.3 (http://www.broadinstitute.org/haploview/haploviewdownloads) was used to assess the linkage disequilibrium structure between SNPs (20). Tagger Software (Cambridge, MA, USA) was used to select tagSNPs with the 'pairwise tagging only' option and an $r^{2}$ threshold of $>0.8( \pm 10 \mathrm{~kb}$ upstream and downstream of the genes). In the tagSNP selection, we forced inclusion of the functional SNP previously studied (rs659366, -866 G/A promoter polymorphism) before running Tagger. At the time of the present study, we selected three tagSNPs - namely rs2306819, rs599277 and rs659366 - representing all of the common genetic variations within the UCP2 gene according to the HapMap data release 24/phase II Nov 08, on NCBI B36 assembly, dbSNP b126. However, we capture only $75 \%$ of the UCP2 gene variations according to the current HapMap data release 27/phases II + III, Feb 09, on NCBI B36 assembly, dbSNP b126.

\section{Genotyping}

Northern Finland Birth Cohort 1966 - For NFBC, genomic DNA was extracted from whole blood using standard methods. All DNA samples for the Illumina Infinium 370cnvDuo array were prepared for genotyping by the Broad Institute Biological Sample Repository (BSP). 
All individuals in the study were genotyped with call rates $>95 \%$. SNPs were excluded from analysis if the call rate in the final sample was $<95 \%$, if the $P$ value from a test of Hardy-Weingberg equilibrium (HWE) was $<0.0001$, or if the minor allele frequency (MAF) was $<1 \%$.

Netherlands Study of Depression and Anxiety $\bullet$ Individual genotyping was conducted by Perlegen Sciences (Mountain View, CA, USA) using a set of four proprietary, high-density oligonucleotide arrays as part of the Genetic Association Information Network (GAIN) (21). Samples were excluded for failing quality control (QC) due to uncertain linkage between genotype and phenotype records, evidence of contamination, missing genotype data, high genome-wide homozygosity $(\sim 75 \%)$, first- or second-degree relationships or non-Caucasian ancestry. SNPs were required not to have any of the following features: gross mapping problem, greater than one genotype disagreements in 40 duplicated samples, greater than one Mendelian inheritance errors in complete trio samples, MAF $<0.01$ or $>0.05$ missing genotypes. A Hardy-Weinberg filter was not used. A total of 435291 SNPs met these criteria and were included in the final analysis data set.

LifeLines Cohort Study $\bullet$ Genotyping for Lifelines was performed on the Illumina CytoSNP12 v2 chip. Samples were excluded based on call rates below 0.95, gender mismatch, duplicate discordance and genetic similarity. Population stratification was assessed by principal component analysis over the sample correlation matrix, based on 16842 independent SNPs. Samples were excluded when for they diverged from the mean with at least three s.D.s ( $Z$-score $>3$ ) for the first five principal components. SNPs were excluded with a MAF of $<0.01$, call rate $<0.95$ or deviation from HWE $\left(P<1 \times 10^{-5}\right)$. Genome wide genotype imputation was performed using Beagle v. 3.1.0, using the NCBI build 36 of phase II HapMap CEU data (release 22) as a reference panel.

\section{Statistical analysis}

All of the SNPs were coded additively and with the effect allele as the minor allele. The metabolic measures GGT and ALT were highly skewed and were therefore dichotomised as normal or high using the population-based reference values (22). Individuals were considered to have high levels of ALT if their ALT value was $>50$ or 38 for men and women respectively. For GGT, the cut-off for high levels was 58 for men and 42 for women.
Logistic regression models were used to evaluate the interaction between the polymorphisms and BMI, WC and alcohol intake on the dichotomised GGT and ALT levels. In all three cohorts, logistic regression models were adjusted for age, gender, high alcohol intake (defined as the top $10 \%$ of the distribution for each sex), obesity (BMI $<30$ vs $\geq 30 \mathrm{~kg} / \mathrm{m}^{2}$ ), diabetes, hypertension and lipid medication or hyperlipidaemia. In the presence of heterogeneity of effects between the studies, we used a random-effects meta-analysis; otherwise, we tested using fixed-effects inverse variance meta-analysis. All analyses were carried out using STATA (College Station, TX, USA), version 12 . A $P$ value of $<0.05$ was considered to be statistically significant.

\section{Results}

As shown in Table 1, in the NFBC 1966 cohort, men had significantly higher BMI $(P<0.001)$ and WC $(P<0.001)$ and a significantly greater proportion of high GGT levels $(P<0.001)$. No significant differences were observed between men and women for proportions of alcohol consumption $(P=0.96)$ and high ALT levels $(P=0.94)$. Similar findings were observed in NESDA and LifeLines, except for proportion of high ALT levels, which were significantly higher in men in both cohorts.

\section{Main effects}

The genotype and allele frequencies of the three UCP2 SNPs are presented in Table 2 and the three SNPs were in HWE $(P>0.05)$. None of the three polymorphisms showed an association with ALT and GGT levels in in the metaanalysis of the three cohorts (Table 3).

\section{Interaction of the UCP2 polymorphisms with alcohol intake and obesity traits on ALT and GGT levels}

Of the three UCP2 polymorphisms, only SNP rs2306819 showed evidence for an interaction with alcohol intake on GGT levels in the NFBC 1966 ( $\left.P_{\text {interaction }}=0.02\right)$. This interaction was, however, not observed in NESDA, LifeLines or in the meta-analysis of the three cohorts ( $P_{\text {interaction }}>0.53$, for all interactions). None of the other interactions with high alcohol intake on GGT levels were significant in the meta-analysis of the three cohorts ( $P_{\text {interaction }}>0.54$, for all; Table 4$)$. There was also no evidence for interaction between the SNPs and alcohol intake on ALT levels in the meta-analysis ( $P_{\text {interaction }}$ $>0.26$, for all). 
Table 1 Clinical and biochemical characteristics of the study participants. Values represented are means \pm s.D.

\begin{tabular}{|c|c|c|}
\hline \multirow{2}{*}{$\begin{array}{l}\text { Clinical and biochemical } \\
\text { parameters }\end{array}$} & \multicolumn{2}{|c|}{ NFBC 1966} \\
\hline & Men $(n=2535)$ & Women $(n=2757)$ \\
\hline Age (years) & 31 & 31 \\
\hline BMI $\left(\mathrm{kg} / \mathrm{m}^{2}\right)$ & $25.2 \pm 3.6$ & $24.2 \pm 4.7$ \\
\hline WC (cm) & $88.9 \pm 9.9$ & $78.9 \pm 12.1$ \\
\hline Obese (\%) & 8.3 & 9.5 \\
\hline Alcohol (g/day) & $13.9 \pm 20.6$ & $4.9 \pm 8.2$ \\
\hline GGT $(U / I)^{a}$ & $20(14,32)$ & $11(8,16)$ \\
\hline High GGT levels (\%) & 8.6 & 2.7 \\
\hline $\operatorname{ALT}(U / I)^{a}$ & $6(2.5,10)$ & $5.5(2.5,9)$ \\
\hline High ALT levels (\%) & 8.6 & 8.7 \\
\hline
\end{tabular}

\begin{tabular}{|c|c|}
\hline \multicolumn{2}{|c|}{ NESDA } \\
\hline Men $(n=622)$ & Women $(n=1303)$ \\
\hline $43.9 \pm 12.0$ & $40.9 \pm 12.7$ \\
\hline $26.3 \pm 4.3$ & $25.3 \pm 5.3$ \\
\hline $96.3 \pm 13.2$ & $85.4 \pm 13.7$ \\
\hline 17.9 & 16.5 \\
\hline $17.5 \pm 22.1$ & $9.2 \pm 13.2$ \\
\hline $26(17.8,39)$ & $15(11,22)$ \\
\hline 12.8 & 5.8 \\
\hline $26.3(19,37)$ & $16.9(13,22)$ \\
\hline 11.3 & 5.3 \\
\hline
\end{tabular}

\begin{tabular}{ccc}
\hline \multicolumn{2}{c}{ LifeLines } \\
\hline Men $(n=5579)$ & & Women $(n=7784)$ \\
\cline { 1 - 1 } $49.0 \pm 11.7$ & & $48.5 \pm 11.3$ \\
$26.7 \pm 3.6$ & & $26.1 \pm 4.7$ \\
$96.6 \pm 10.5$ & & $88.5 \pm 12.2$ \\
15.4 & & 17.3 \\
$13.9 \pm 12.8$ & & $4.1 \pm 6.8$ \\
$27(20,39)$ & & $17(13,23)$ \\
10.4 & & 6.26 \\
$26(20,35)$ & $17(13,22)$ \\
8.77 & 4.12 \\
\hline
\end{tabular}

${ }^{\mathrm{a}}$ For GGT and ALT levels, values presented are medians (interquartile range).

In contrast, in the analyses on obesity-related traits in the NFBC 1966, all of the three UCP2 polymorphisms showed an interaction with BMI $\left(P_{\text {interaction }}<0.04\right)$ and WC $\left(P_{\text {interaction }}<0.004\right)$ on GGT levels, while two polymorphisms (rs599277 and rs659366) also suggested an interaction with obesity (as a binary trait) on GGT $\left(P_{\text {interaction }}<0.03\right)$ (Table 5). The meta-analysis of the three cohorts confirmed the interactions between the SNP rs659366 and WC and BMI on GGT levels (WC, $P_{\text {interaction- }}$ $=0.03$ and BMI, $P_{\text {interaction }}=0.007$ ), while for the other two polymorphisms (rs599277 and rs2306819), evidence for interaction was not consistent; the SNP rs2306819 showed an interaction with WC $\left(P_{\text {interaction }}=0.04\right)$ but not BMI $\left(P_{\text {interaction }}=0.08\right)$ and obesity $\left(P_{\text {interaction }}=0.22\right)$, and SNP rs599277 showed an interaction with BMI ( $P_{\text {interaction- }}$ $=0.01)$ and obesity $\left(P_{\text {interaction }}=0.03\right)$ but not WC
$\left(P_{\text {interaction }}=0.09\right) \quad($ Table 5$)$. None of the interactions between the three SNPs with obesity traits on ALT levels were statistically significant (data not shown).

\section{Discussion}

The important finding of our study is that the effect of UCP2 gene polymorphisms on liver function (as measured by GGT and ALT levels) is likely to be modified by levels of body fat rather than alcohol intake. Our meta-analysis in 20242 individuals suggested that the functional UCP2 gene polymorphism, rs65966, interacts with both WC (measure of central body fat distribution) and BMI (measure of body fat levels) on its influence on GGT levels. This finding is in line with the role of UCP2 in the accumulation of fat in the hepatocytes (6), which is likely

Table 2 The genotype and allele frequencies of the three UCP2 gene polymorphisms in the three cohorts stratified by gender.

\begin{tabular}{|c|c|c|c|c|c|c|}
\hline \multirow{2}{*}{$\begin{array}{l}\text { UCP2 } \\
\text { polymorphisms }\end{array}$} & \multicolumn{2}{|c|}{ NFBC 1966} & \multicolumn{2}{|c|}{ NESDA $^{a}$} & \multicolumn{2}{|c|}{ LifeLines } \\
\hline & Men & Women & Men & Women & Men & Women \\
\hline \multicolumn{7}{|l|}{ rs2306819 } \\
\hline $\mathrm{CC}$ & 1232 & 1329 & 276.11 & 584.61 & 2188 & 3056 \\
\hline CT & 1051 & 1132 & 296.02 & 569.78 & 2801 & 3862 \\
\hline $\mathrm{TT}$ & 236 & 272 & 49.62 & 148.17 & 590 & 866 \\
\hline MAF (\%) & 30 & 31 & 32 & 33 & 36 & 36 \\
\hline \multicolumn{7}{|l|}{ rs599277 } \\
\hline GG & 640 & 700 & 200.41 & 396.30 & 1715 & 2415 \\
\hline AG & 1202 & 1332 & 317.42 & 638.30 & 2806 & 3827 \\
\hline $\mathrm{AA}$ & 621 & 668 & 103.77 & 267.48 & 1058 & 1542 \\
\hline MAF (\%) & 50 & 49 & 42 & 45 & 44 & 44 \\
\hline \multicolumn{7}{|l|}{ rs659366 } \\
\hline $\mathrm{CC}$ & 944 & 1024 & 248.99 & 514.22 & 2179 & 3022 \\
\hline $\mathrm{CT}$ & 1201 & 1309 & 295.03 & 616.22 & 2616 & 3610 \\
\hline $\mathrm{TT}$ & 395 & 432 & 77.65 & 171.85 & 784 & 1152 \\
\hline MAF (\%) & 39 & 39 & 36 & 37 & 37 & 38 \\
\hline
\end{tabular}


Table 3 Association of the UCP2 gene polymorphisms with ALT and GGT levels.

\begin{tabular}{|c|c|c|}
\hline \multirow[b]{2}{*}{ Study cohorts } & \multicolumn{2}{|c|}{ rs2306819 } \\
\hline & $\beta \pm$ S.E.M. & $P$ value* \\
\hline \multicolumn{3}{|l|}{ ALT levels } \\
\hline NFBC 1966 & $-0.03 \pm 0.09$ & 0.74 \\
\hline NESDA & $0.09 \pm 0.15$ & 0.54 \\
\hline LifeLines & $-0.03 \pm 0.06$ & 0.65 \\
\hline Meta-analysis & $0.05 \pm 0.68$ & 0.68 \\
\hline \multicolumn{3}{|l|}{ GGT levels } \\
\hline NFBC 1966 & $-0.14 \pm 0.11$ & 0.21 \\
\hline NESDA & $0.01 \pm 0.15$ & 0.93 \\
\hline LifeLines & $0.04 \pm 0.05$ & 0.42 \\
\hline Meta-analysis & $0.008 \pm 0.04$ & 0.85 \\
\hline
\end{tabular}

\begin{tabular}{|c|c|}
\hline \multicolumn{2}{|c|}{ rs599277 } \\
\hline$\beta \pm$ S.E.M. & $P$ value* \\
\hline$-0.11 \pm 0.08$ & 0.17 \\
\hline $0.04 \pm 0.14$ & 0.79 \\
\hline $0.01 \pm 0.05$ & 0.80 \\
\hline $0.04 \pm 0.63$ & 0.63 \\
\hline$-0.002 \pm 0.09$ & 0.98 \\
\hline$-0.10 \pm 0.14$ & 0.46 \\
\hline $0.06 \pm 0.05$ & 0.24 \\
\hline $0.03 \pm 0.04$ & 0.44 \\
\hline
\end{tabular}

\begin{tabular}{|c|c|}
\hline \multicolumn{2}{|c|}{ rs659366 } \\
\hline$\beta \pm$ S.E.M. & $P$ value* \\
\hline$-0.09 \pm 0.08$ & 0.30 \\
\hline$-0.19 \pm 0.15$ & 0.19 \\
\hline $0.03 \pm 0.05$ & 0.62 \\
\hline $0.04 \pm 0.57$ & 0.57 \\
\hline $0.04 \pm 0.10$ & 0.67 \\
\hline$-0.17 \pm 0.15$ & 0.23 \\
\hline $0.07 \pm 0.05$ & 0.14 \\
\hline $0.05 \pm 0.04$ & 0.27 \\
\hline
\end{tabular}

*P values adjusted for age, gender, high alcohol intake, obesity, diabetes, hypertension and lipid medication/hyperlipidaemia.

to result in an elevation of GGT levels due to resultant liver dysfunction.

Given the role of UCP2 in the control of energy metabolism (23), polymorphisms in the UCP2 gene have been examined for their associations with obesity and its related traits. The three commonly studied polymorphisms in the UCP2 gene are $-866 \mathrm{G} / \mathrm{A}$ polymorphism in the promoter region, the Ala55Val polymorphism in the exon 4 and the $45 \mathrm{bp}$ insertion/deletion polymorphism in the 3'-UTR. These polymorphisms have been shown to be associated with various metabolic traits such as obesity (24), body fat distribution (25), resting energy expenditure (26), type 2 diabetes (10) and insulin resistance $(9,27)$ in various populations from different ethnic backgrounds (24). However, there were also studies that failed to show an association between these polymorphisms and metabolic traits $(8,28,29)$. These inconsistencies could be attributed to the small sample size, incomplete coverage of the UCP2 gene variations or potential population-specific influences on metabolic traits (29). Hence, in our study we have performed a meta-analysis of data from three large European cohorts ( $n$ up to 20242 ) and used the tagSNP approach to capture all common genetic variations within the UCP2 gene. Even though the study protocol used in the three cohorts were different and the participants were from different geographical regions and age groups, the three cohorts were of European ethnicity and the analyses were adjusted for age, gender, alcohol consumption, obesity, diabetes, hypertension and lipid medication. However, we cannot completely rule out the effects of other diseases (such as mental health-related outcomes in NESDA) on our analysis.

Independent of the associations with obesity and diabetes, UCP2 has also been implicated in non-alcoholic fatty liver disease (NAFLD) (30). UCP2 gene expression has been shown to be increased in the liver of rats with NAFLD (31); however, the real effect of UCP2 on NAFLD is still unclear. Several mechanisms have been hypothesised $(6,30)$, and the accumulating evidence supports the role of mitochondrial dysfunction in NAFLD, in which UCP2

Table 4 Interaction between UCP2 gene polymorphisms and high alcohol intake on ALT and GGT levels.

\begin{tabular}{|c|c|}
\hline Study cohorts & rs2306819 \\
\hline \multicolumn{2}{|c|}{$\beta$ coefficients \pm S.E.M. $\left(P\right.$ values $\left.{ }^{*}\right)$ for interaction on ALT levels } \\
\hline NFBC 1966 & $-0.14 \pm 0.27(0.61)$ \\
\hline NESDA & $0.05 \pm 0.38(0.89)$ \\
\hline LifeLines & $0.14 \pm 0.16(0.37)$ \\
\hline Meta-analysis & $0.07 \pm 0.13(0.59)$ \\
\hline \multicolumn{2}{|c|}{$\beta$ coefficients \pm s.E.M. ( $P$ values*) for interaction on GGT levels } \\
\hline NFBC 1966 & $0.58 \pm 0.25(0.02)$ \\
\hline NESDA & $-0.13 \pm 0.35(0.70)$ \\
\hline LifeLines & $-0.03 \pm 0.13(0.79)$ \\
\hline Meta-analysis & $0.07 \pm 0.11(0.53)$ \\
\hline
\end{tabular}

$\begin{array}{r}\hline \text { rs599277 } \\ \hline 0.16 \pm 0.23(0.50) \\ 0.35 \pm 0.37(0.35) \\ 0.16 \pm 0.15(0.29) \\ 0.18 \pm 0.12(0.89) \\ 0.39 \pm 0.23(0.09) \\ -0.09 \pm 0.33(0.77) \\ -0.005 \pm 0.12(0.97) \\ 0.06 \pm 0.09(0.54) \\ \hline\end{array}$

\begin{tabular}{c}
\hline rs659366 \\
\hline $0.11 \pm 0.24(0.64)$ \\
$0.25 \pm 0.39(0.52)$ \\
$0.13 \pm 0.15(0.40)$ \\
$0.14 \pm 0.12(0.26)$ \\
\\
$0.42 \pm 0.23(0.07)$ \\
$-0.24 \pm 0.35(0.49)$ \\
$-0.06 \pm 0.12(0.62)$ \\
$0.02 \pm 0.10(0.85)$ \\
\hline
\end{tabular}

* $P$ values adjusted for age, gender, obesity, diabetes, hypertension and lipids. 
Table 5 Interaction between UCP2 gene polymorphisms and obesity, BMI and WC on GGT levels.

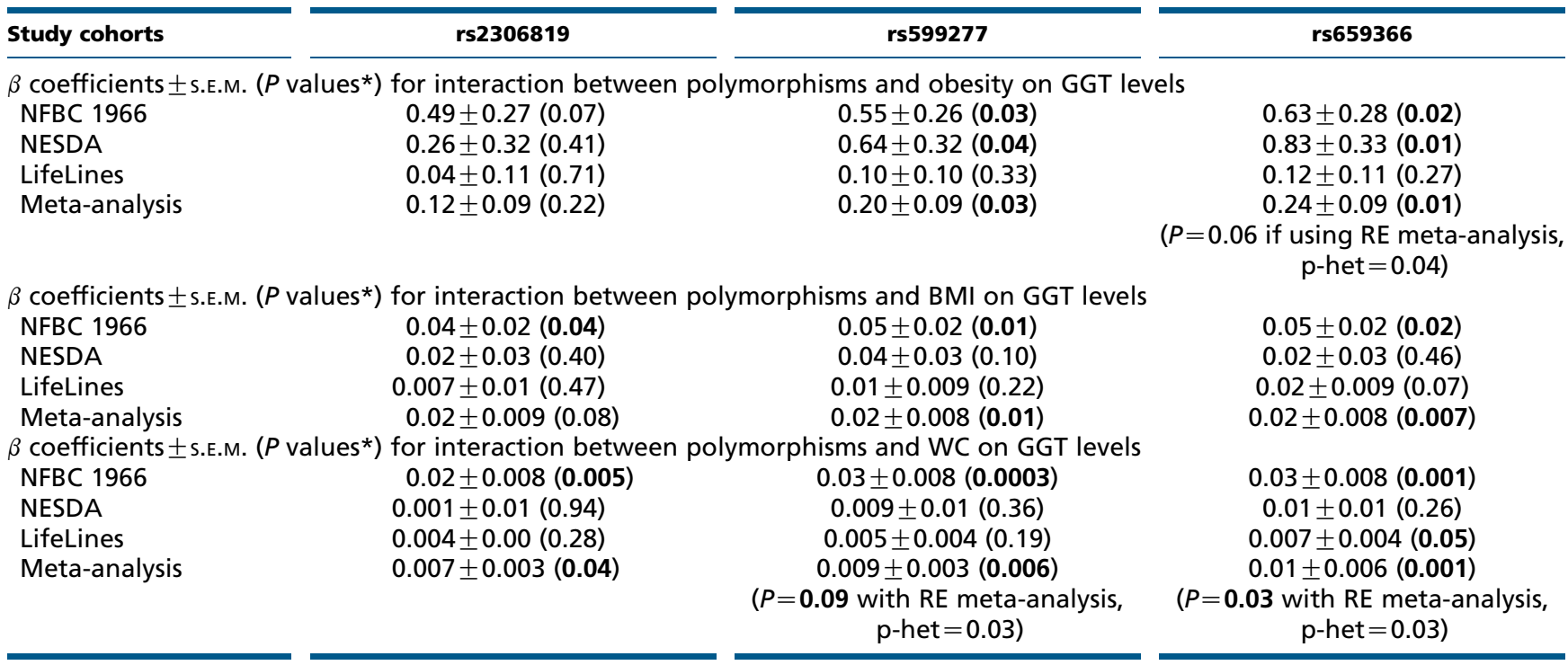

RE, random-effects; $p$-het, $P$ value for heterogeneity between the studies. ${ }^{*} P$ values adjusted for age, gender, high alcohol intake, diabetes, hypertension and lipids.

plays a vital role through its uncoupling of oxidative phosphorylation (32). Further to the role of UCP2 in NAFLD, UCP2 also has shown to stimulate protective peripheral and central neural mechanisms in acute ethanol intake (7). Hence, we aimed to investigate the hypothesis (2) that alcohol intake could have an adverse effect on liver function in individuals with gain of function polymorphisms of the UCP2 gene that is not seen in non-drinkers. One of the reasons for alcohol intake not being an effect modifier in the link between UCP2 polymorphisms and GGT/ALT levels in this large-scale meta-analysis could be because of the fact that the effect of drugs on the observed association was not excluded.

Even though the interaction between the UCP2 gene polymorphism, rs659366, and WC and BMI on GGT levels was not significant in all the cohorts, there was a consistent interaction of rs659366 with WC and BMI on GGT levels in the meta-analysis of the three cohorts. Findings from previous studies $(25,33)$ have also implicated the role of UCP2 gene polymorphism, rs659366, in WC and body fat composition, and hence, our results are suggestive of the role of body fat as a possible effect modifier of the link between UCP2 and liver dysfunction.

The interaction between UCP2 and WC was observed only when examining GGT levels as an outcome. Although both ALT and GGT levels have been used as indicators of liver dysfunction, GGT levels have been shown to be better than ALT as predictors of metabolic traits such as diabetes (34). Also, some studies have demonstrated a stronger association between GGT and diabetes than between ALT and diabetes $(35,36)$. Furthermore, GGT levels have been considered to have the potential to be included in algorithms for metabolic syndrome, because the predictive value in the diagnosis of metabolic syndrome is higher for GGT as compared to ALT (37). Hence, it is possible that the GGT levels, rather than ALT, might be a marker of a mechanism that is responsible for interaction between the UCP2 polymorphism and body fat in our study.

Previous studies have functionally characterized the role of the UCP2 gene promoter polymorphism $-866 \mathrm{G} / \mathrm{A}$ (rs659366) in obesity and diabetes $(38,39)$. The WT G allele of the polymorphism has been shown to be associated with enhanced adipose tissue mRNA expression in vivo, reduced transcriptional activity in vitro and increased risk of obesity (39). Also, the same polymorphism has been shown to affect the preferential binding of PAX6 (a pancreatic transcription factor involved in pancreatic $\beta$-cell development and function) to the UCP2 gene promoter (38). In line with the functionality of this polymorphism, our finding raises the question of whether this polymorphism interacts with body fat in altering GGT levels through a pathway independent of obesity and diabetes. Hence, mechanistic studies are required to understand the role of this functional polymorphism in relation to body fat and liver function. 
In summary, our study, in up to 20242 individuals, shows evidence for an interaction between UCP2 gene polymorphism, rs659366, and WC and BMI on GGT levels, suggesting that UCP2 gene polymorphisms may cause liver dysfunction through the interaction with body fat rather than alcohol intake. Further large studies are required to confirm this finding and should focus on considering the effect of drugs when testing for the interaction with alcohol intake.

\section{Declaration of interest}

The authors declare that there is no conflict of interest that could be perceived as prejudicing the impartiality of the research reported.

\section{Funding}

The study was supported by the British Heart Foundation (grant number PG/09/023) and the Academy of Finland. Research at the University College London, Institute of Child Health, and Great Ormond Street Hospital for Children National Health Service (NHS) Trust benefits from research and development funding received from the NHS Executive.

$\mathrm{P}$ Elliott is director of the MRC-PHE Centre for Environment and Health and acknowledges support from the Medical Research Council and Public Health England. P Elliott is a National Institute for Health Research (NIHR) senior investigator and acknowledges support from the NIHR Biomedical Research Centre at Imperial College Healthcare NHS Trust and Imperial College London and the NIHR Health Protection Research Unit on Health Effects of Environmental Hazards.

LifeLines Cohort Study: The LifeLines Cohort Study, and generation and management of genome-wide association studies (GWAS) genotype data for the LifeLines Cohort Study, is supported by The Netherlands Organization of Scientific Research NWO (grant number 175.010.2007.006); Economic Structure Enhancing Fund (FES) of the Dutch government; Ministry of Economic Affairs; the Ministry of Education, Culture and Science; Ministry for Health, Welfare and Sports; the Northern Netherlands Collaboration of Provinces (SNN); Province of Groningen; University Medical Center Groningen; University of Groningen; Dutch Kidney Foundation and Dutch Diabetes Research Foundation.

Northern Finland Birth Cohort 1966: NFBC 1966 received financial support from the Academy of Finland (project grants 104781, 120315, 129269, 1114194 and 24300796, Center of Excellence in Complex Disease Genetics and SALVE); University Hospital Oulu, Biocenter, University of Oulu, Finland (75617); NHLBI grant number 5R01HL087679-02 through the STAMPEED program (1RL1MH083268-01); NIH/NIMH (5R01MH63706:02); ENGAGE project and grant agreement HEALTH-F4-2007-201413; EU FP7 EurHEALTHAgeing, 277849; Medical Research Council, UK (G0500539, G0600705, G1002319, PrevMetSyn/SALVE) and the MRC, Centenary Early Career Award. The program is currently being funded by the $\mathrm{H} 2020-633595$ DynaHEALTH action and academy of the Finland EGEA-project.

The DNA extractions, sample QCs, biobank upkeeping and aliquotting was performed in the National Public Health Institute, Biomedicum Helsinki, Finland, and supported financially by the Academy of Finland and Biocentrum Helsinki.

Author contribution statement

K S Vimaleswaran, R D Cohen, B J Boucher and E Hyppönen conceived and designed the study and drafted the manuscript; A Cavadino, N Verweij,
I M Leach, J Auvinen, P Elliott, B W Penninx, M-R Järvelin and P v d Harst contributed to the study design; A Cavadino performed the statistical analysis; I M Nolte, I M Leach, J Veijola, H Snieder and B J Boucher provided a critical review of the manuscript. All authors read and approved the final manuscript.

\section{Acknowledgements}

We thank the late Prof. Paula Rantakallio (launch of NFBCs) and Ms Out Tornwall and Ms Minttu Jussila (DNA biobanking). The authors would like to acknowledge the contribution of the late Academian of Science Leena Peltonen. We also thank Behrooz Alizadeh, Annemieke Boesjes, Marcel Bruinenberg, Noortje Festen, P v d Harst, I M Nolte, Lude Franke and Mitra Valimohammadi for their help in creating the GWAS database, and Rob Bieringa, Joost Keers, René Oostergo, Rosalie Visser and Judith Vonk for their work related to data collection and validation.

The authors are grateful to the study participants, the staff from the LifeLines Cohort Study and the contributing research centers delivering data to LifeLines and the participating general practitioners and pharmacists. LifeLines group author genetics: LifeLines Cohort Study: Behrooz Z Alizadeh: Department of Epidemiology, University Medical Center Groningen, University of Groningen, The Netherlands; Paul I W de Bakker: Department of Medical Genetics, Center for Molecular Medicine, University Medical Center Utrecht, The Netherlands and Department of Epidemiology, Julius Center for Health Sciences and Primary Care, University Medical Center Utrecht, The Netherlands; H Marike Boezen: Department of Epidemiology, University Medical Center Groningen, University of Groningen, The Netherlands; P v d Harst: Department of Cardiology, University Medical Center Groningen, University of Groningen, The Netherlands; Gerjan Navis: Division of Nephrology, Department of Internal Medicine, University Medical Center Groningen, University of Groningen, The Netherlands; Marianne Rots: Department of Medical Biology, University Medical Center Groningen, University of Groningen, The Netherlands; $H$ Snieder: Department of Epidemiology, University Medical Center Groningen, University of Groningen, The Netherlands; Ronald P Stolk: Department of Epidemiology, University Medical Center Groningen, University of Groningen, The Netherlands and LifeLines Cohort Study, University Medical Center Groningen, University of Groningen, The Netherlands; Morris Swertz: Department of Genetics, University Medical Center Groningen, University of Groningen, The Netherlands; Bruce H R Wolffenbuttel: Department of Endocrinology, University Medical Center Groningen, University of Groningen, The Netherlands; Cisca Wijmenga: Department of Genetics, University Medical Center Groningen, University of Groningen, The Netherlands.

\section{References}

1 Chevillotte E, Giralt M, Miroux B, Ricquier D \& Villarroya F. Uncoupling protein-2 controls adiponectin gene expression in adipose tissue through the modulation of reactive oxygen species production. Diabetes 200756 1042-1050. (doi:10.2337/db06-1300)

2 Cohen RD, Brown CL, Nickols C, Levey P, Boucher BJ, Greenwald SE \& Wang W. Inbuilt mechanisms for overcoming functional problems inherent in hepatic microlobular structure. Computational and Mathematical Methods in Medicine 20112011 185845. (doi:10.1155/ 2011/185845)

3 Hodny Z, Kolarova P, Rossmeisl M, Horakova M, Nibbelink M, Penicaud L, Casteilla L \& Kopecky J. High expression of uncoupling protein 2 in foetal liver. FEBS Letters 1998425 185-190. (doi:10.1016/ S0014-5793(98)00230-0)

4 Cortez-Pinto H, Yang SQ, Lin HZ, Costa S, Hwang CS, Lane MD, Bagby G \& Diehl AM. Bacterial lipopolysaccharide induces uncoupling protein-2 expression in hepatocytes by a tumor necrosis 
factor- $\alpha$-dependent mechanism. Biochemical and Biophysical Research Communications 1998251 313-319. (doi:10.1006/bbrc.1998.9473)

5 Chavin KD, Yang S, Lin HZ, Chatham J, Chacko VP, Hoek JB, Walajtys-Rode E, Rashid A, Chen $\mathrm{CH}$, Huang CC et al. Obesity induces expression of uncoupling protein-2 in hepatocytes and promotes liver ATP depletion. Journal of Biological Chemistry 1999274 5692-5700. (doi:10.1074/jbc.274.9.5692)

6 Baffy G. Uncoupling protein-2 and non-alcoholic fatty liver disease. Frontiers in Bioscience 200510 2082-2096. (doi:10.2741/1683)

7 Horvath B, Spies C, Horvath G, Kox WJ, Miyamoto S, Barry S, Warden $\mathrm{CH}$, Bechmann I, Diano S, Heemskerk J et al. Uncoupling protein 2 (UCP2) lowers alcohol sensitivity and pain threshold. Biochemical Pharmacology 200264 369-374. (doi:10.1016/S00062952(02)01167-X)

8 Qian L, Xu K, Xu X, Gu R, Liu X, Shan S \& Yang T. UCP2 -866G/A, Ala55Val and UCP3 $-55 \mathrm{C} / \mathrm{T}$ polymorphisms in association with obesity susceptibility - a meta-analysis study. PLoS ONE 20138 e58939. (doi:10.1371/journal.pone.0058939)

9 Andersen G, Dalgaard LT, Justesen JM, Anthonsen S, Nielsen T, Thorner LW, Witte D, Jorgensen T, Clausen JO, Lauritzen T et al. The frequent UCP2 $-866 \mathrm{G}>$ A polymorphism protects against insulin resistance and is associated with obesity: a study of obesity and related metabolic traits among 17636 Danes. International Journal of Obesity 201337 175-181. (doi:10.1038/ijo.2012.22)

10 Vimaleswaran KS, Radha V, Ghosh S, Majumder PP, Sathyanarayana Rao MR \& Mohan V. Uncoupling protein 2 and 3 gene polymorphisms and their association with type 2 diabetes in Asian Indians. Diabetes Technology \& Therapeutics 201113 19-25. (doi:10.1089/dia.2010.0091)

11 Gable DR, Stephens JW, Cooper JA, Miller GJ \& Humphries SE. Variation in the UCP2-UCP3 gene cluster predicts the development of type 2 diabetes in healthy middle-aged men. Diabetes $2006 \mathbf{5 5}$ 1504-1511. (doi:10.2337/db05-1645)

12 Patapoutian A, Peier AM, Story GM \& Viswanath V. ThermoTRP channels and beyond: mechanisms of temperature sensation. Nature Reviews. Neuroscience 20034 529-539. (doi:10.1038/nrn1141)

13 Burns SP, Desai M, Cohen RD, Hales CN, Iles RA, Germain JP, Going TC $\&$ Bailey RA. Gluconeogenesis, glucose handling, and structural changes in livers of the adult offspring of rats partially deprived of protein during pregnancy and lactation. Journal of Clinical Investigation 1997100 1768-1774. (doi:10.1172/JCI119703)

14 Bulotta A, Ludovico O, Coco A, Di Paola R, Quattrone A, Carella M, Pellegrini F, Prudente S \& Trischitta V. The common -866G/A polymorphism in the promoter region of the UCP-2 gene is associated with reduced risk of type 2 diabetes in Caucasians from Italy. Journal of Clinical Endocrinology and Metabolism 200590 1176-1180. (doi:10.1210/ jc.2004-1072)

15 Cohen RD. The metabolic background to acid-base homeostasis and some of its disorders, In The Metabolic and Molecular Basis of Acquired Disease (Eds.) RD Cohen, B Lewis, KG Alberti et al. pp 962-1001. London: Bailliere Tindall, 1990.

16 Jungermann K \& Katz N. Functional specialization of different hepatocyte populations. Physiological Reviews 198969 708-764.

17 Jarvelin MR, Sovio U, King V, Lauren L, Xu B, McCarthy MI, Hartikainen AL, Laitinen J, Zitting P, Rantakallio P et al. Early life factors and blood pressure at age 31 years in the 1966 Northern Finland birth cohort. Hypertension $2004 \mathbf{4 4} 838-846$. (doi:10.1161/01.HYP. 0000148304.33869.ee)

18 Penninx BW, Beekman AT, Smit JH, Zitman FG, Nolen WA, Spinhoven P, Cuijpers P, De Jong PJ, Van Marwijk HW, Assendelft WJ et al. The Netherlands Study of Depression and Anxiety (NESDA): rationale, objectives and methods. International Journal of Methods in Psychiatric Research 200817 121-140. (doi:10.1002/mpr.256)

19 Poikolainen K, Vartiainen E \& Korhonen HJ. Alcohol intake and subjective health. American Journal of Epidemiology 1996144 346-350. (doi:10.1093/oxfordjournals.aje.a008935)
20 Barrett JC, Fry B, Maller J \& Daly MJ. Haploview: analysis and visualization of LD and haplotype maps. Bioinformatics 200521 263-265. (doi:10.1093/bioinformatics/bth457)

21 Sullivan PF, de Geus EJ, Willemsen G, James MR, Smit JH, Zandbelt T, Arolt V, Baune BT, Blackwood D, Cichon S et al. Genome-wide association for major depressive disorder: a possible role for the presynaptic protein piccolo. Molecular Psychiatry 200914 359-375. (doi:10.1038/mp.2008.125)

22 Leino A, Impivaara O, Irjala K, Maki J, Peltola O \& Jarvisalo J. Healthbased reference intervals for ALAT, ASAT and GT in serum, measured according to the recommendations of the European Committee for Clinical Laboratory Standards (ECCLS). Scandinavian Journal of Clinical and Laboratory Investigation 199555 243-250. (doi:10.3109/ 00365519509089619)

23 Fleury C, Neverova M, Collins S, Raimbault S, Champigny O, Levi-Meyrueis C, Bouillaud F, Seldin MF, Surwit RS, Ricquier D et al. Uncoupling protein-2: a novel gene linked to obesity and hyperinsulinemia. Nature Genetics 199715 269-272. (doi:10.1038/ ng0397-269)

24 Liu L, Zhao X, Kang S \& Zhang D. An association between -866G/A polymorphism in the promoter of UCP2 and obesity: a meta-analysis. Gene 2013514 41-47. (doi:10.1016/j.gene.2012.11.001)

25 Martinez-Hervas S, Mansego ML, de Marco G, Martinez F, Alonso MP, Morcillo S, Rojo-Martinez G, Real JT, Ascaso JF, Redon J et al. Polymorphisms of the UCP2 gene are associated with body fat distribution and risk of abdominal obesity in Spanish population. European Journal of Clinical Investigation 201242 171-178. (doi:10.1111/ j.1365-2362.2011.02570.x)

26 Astrup A, Toubro S, Dalgaard LT, Urhammer SA, Sorensen TI \& Pedersen O. Impact of the $\mathrm{v} / \mathrm{v} 55$ polymorphism of the uncoupling protein 2 gene on 24-h energy expenditure and substrate oxidation. International Journal of Obesity and Related Metabolic Disorders 199923 1030-1034. (doi:10.1038/sj.ijo.0801040)

27 Ochoa MC, Santos JL, Azcona C, Moreno-Aliaga MJ, MartinezGonzalez MA, Martinez JA, Marti A \& Members G. Association between obesity and insulin resistance with UCP2-UCP3 gene variants in Spanish children and adolescents. Molecular Genetics and Metabolism 200792 351-358. (doi:10.1016/j.ymgme.2007.07.011)

28 Leon-Mimila P, Villamil-Ramirez H, Villalobos-Comparan M, Villarreal-Molina T, Romero-Hidalgo S, Lopez-Contreras B, GutierrezVidal R, Vega-Badillo J, Jacobo-Albavera L, Posadas-Romeros C et al. Contribution of common genetic variants to obesity and obesityrelated traits in Mexican children and adults. PLOS ONE 20138 e70640. (doi:10.1371/journal.pone.0070640)

29 de Souza BM, Brondani LA, Boucas AP, Sortica DA, Kramer CK, Canani LH, Leitao CB \& Crispim D. Associations between UCP1 $-3826 \mathrm{~A} / \mathrm{G}$, UCP2 -866G/A, Ala55Val and Ins/Del, and UCP3 - 55C/T polymorphisms and susceptibility to type 2 diabetes mellitus: case-control study and meta-analysis. PLoS ONE 20138 e54259. (doi:10.1371/journal.pone.0054259)

30 Jin X, Xiang Z, Chen YP, Ma KF, Ye YF \& Li YM. Uncoupling protein and nonalcoholic fatty liver disease. Chinese Medical Journal 2013126 3151-3155.

$31 \mathrm{Xu}$ J, Li N, Wang J, Zhang C, Ding S \& Jiao Y. Hepatic SIRT1 and UCP2 expressions in rats with type 2 diabetes mellitus and nonalcoholic fatty liver. Nan Fang Yi Ke Da Хие Хие Bao 201232 726-729.

32 Krauss S, Zhang CY \& Lowell BB. The mitochondrial uncouplingprotein homologues. Nature Reviews. Molecular Cell Biology 20056 248-261. (doi:10.1038/nrm1592)

33 Zheng Y, Xiang K, Zhang R, Jia W, Lu J, Tang J \& Li J. The association between A55V variant in UCP2 gene and body fat distribution, serum lipid profile in Chinese. Zhonghua Yi Xue Yi Chuan Xue Za Zhi 200017 97-100.

34 Fraser A, Harris R, Sattar N, Ebrahim S, Davey Smith G \& Lawlor DA. Alanine aminotransferase, $\gamma$-glutamyltransferase, and incident 
diabetes: the British Women's Heart and Health Study and meta-analysis. Diabetes Care 200932 741-750. (doi:10.2337/ dc08-1870)

35 Andre P, Balkau B, Born C, Royer B, Wilpart E, Charles MA \& Eschwege E. Hepatic markers and development of type 2 diabetes in middle aged men and women: a three-year follow-up study. The D.E.S.I.R. Study (Data from an Epidemiological Study on the Insulin Resistance syndrome). Diabetes \& Metabolism 200531 542-550. (doi:10.1016/S1262-3636(07)70229-X)

36 Wannamethee SG, Shaper AG, Lennon L \& Whincup PH. Hepatic enzymes, the metabolic syndrome, and the risk of type 2 diabetes in older men. Diabetes Care 200528 2913-2918. (doi:10.2337/diacare.28. 12.2913)
37 Kasapoglu B, Turkay C, Bayram Y \& Koca C. Role of GGT in diagnosis of metabolic syndrome: a clinic-based cross-sectional survey. Indian Journal of Medical Research 2010132 56-61.

38 Krempler F, Esterbauer H, Weitgasser R, Ebenbichler C, Patsch JR, Miller K, Xie M, Linnemayr V, Oberkofler H \& Patsch W. A functional polymorphism in the promoter of UCP2 enhances obesity risk but reduces type 2 diabetes risk in obese middle-aged humans. Diabetes 200251 3331-3335. (doi:10.2337/diabetes.51.11.3331)

39 Esterbauer H, Schneitler C, Oberkofler H, Ebenbichler C, Paulweber B, Sandhofer F, Ladurner G, Hell E, Strosberg AD, Patsch JR et al. A common polymorphism in the promoter of UCP2 is associated with decreased risk of obesity in middle-aged humans. Nature Genetics 2001 28 178-183. (doi:10.1038/88911)

Received 17 August 2015

Revised version received 23 September 2015

Accepted 30 September 2015 